\section{Dolor abdominal por extrusión discal dorsal}

\section{Sr. Director:}

La incidencia de hernia discal torácica (HDT) es de 0,25-1\% de todas las hernias discales, y de 1 caso/millón de habitantes/año. El máximo pico de incidencia es entre los 30-50 años sin existir diferencias significativas en cuanto al sexo. La prevalencia de la HDT es del 11-37\% en pacientes asintomáticos. Del 0,15-4 \% requieren tratamiento quirúrgico (1).

\section{Caso clínico}

Mujer de 57 años con dolor subagudo recurrente en hipocondrio derecho. Refería irradiación del dolor a zona dorsal baja derecha, de características mixtas, náuseas, afebril y síntomas miccionales, por lo que se sospechaba causa urológica. Antecedente de litiasis renal, apendicectomía e histerectomía. A la exploración física presenta un abdomen blando y depresible, doloroso, sin masas ni visceromegalias. Peristaltismo normal. Sucusión renal negativa. Dolor a la palpación en zona paravertebral derecha, Lassegue y Bragard negativo; no existe déficit neurológico en EE. II. El estudio de hemograma y bioquímica de sangre y orina no mostró alteraciones.
Ecografía y TAC abdómino-pélvico sin hallazgos. RM dorsal y lumbar: discopatía degenerativa D8-D9, asociando cambios reactivos discopáticos en la esponjosa adyacente a la porción anterior de los platillos, con características de edema óseo (fenómenos de tipo Modic I). A este mismo nivel existe una hernia discal con características de extrusión, en localización paramedial derecha (Fig. 1). Se descarta tratamiento quirúrgico por la no existencia de afectación neurológica, por lo que se realiza tratamiento rehabilitador con manejo del dolor con analgesia de tercer escalón de la OMS (asociación de gabapentina y tramadol oral). A los seis meses el dolor ha disminuido y el estudio de RM de control mostró estabilidad de la hernia.

\section{Discusión}

La restricción del movimiento a nivel torácico y la elevada estabilidad de esta zona, favorecen la baja prevalencia de la herniación discal a este nivel. Otra de las razones es que el núcleo pulposo deriva embriológicamente de la notocorda y, en general, los restos de notocorda son más frecuentes a nivel cervical y lumbar bajo (2). El $75 \%$ de las HDT se presentan por debajo de la octava vértebra torácica
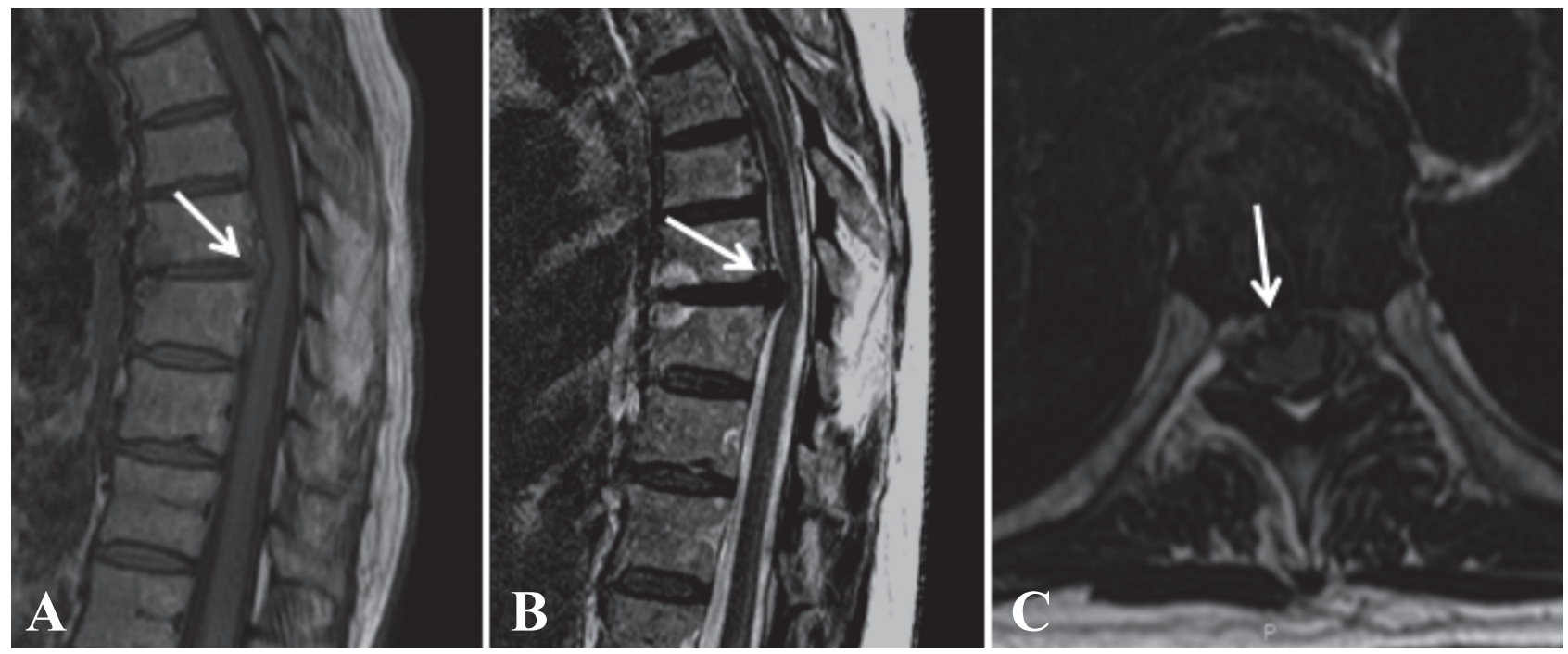

Fig. 1. Imágenes de resonancia magnética. Secuencias sagitales potenciadas en T1 (A), T2 (B) y axial T2 (C), las cuales muestran una protrusión discal paramedial derecha (flecha) que oblitera por completo focalmente el espacio subaracnoideo anterior, contactando y deformando con el cordón medular. 
y la mayoría entre D11-D12, debido a que en este segmento existe mayor movilidad. En el $25 \%$ existe un antecedente traumático. Rara vez la hernia discal dorsal es blanda, no calcificada y puramente lateral (3).

La HDT puede provocar dolor dorsal, dolor radicular y/o mielopatía. Los síntomas de presentación más comunes son: dolor en $76 \%$ de los casos, afectación de esfínteres en $24 \%$, y afectación sensitivomotora en $61 \%$ de los casos, otras presentaciones atípicas son: estreñimiento, vejiga hipotónica, anestesia en silla de montar, disfunción intestinal, náuseas y gastroparesia. La determinación más precisa mediante las modalidades del estudio por imagen (RM) hace que la detección incidental de las anomalías de los discos torácicos aparezca con mayor frecuencia (4).

Los casos con mielopatía tienen una clara indicación de cirugía, no tanto es así en los casos exclusivos de dolor radicular o axial. El porcentaje de mejoría clínica postoperatoria en los casos de radiculopatía es de un $75 \%$, y en los casos de mielopatía una mejoría del $38 \%$. En el $58 \%$ hay una estabilidad clínica y un empeoramiento en $2 \%$ de los casos (5).

\section{Conclusión}

La patología degenerativa dorsal sintomática es menos frecuente que la cervicolumbar y de diagnóstico más demorado. La hernia discal dorsal es la menos frecuente de todas las del raquis, con el menor porcentaje de necesidad quirúrgica. Predomina en el segmento dorsal bajo por las características biomecánicas. Es fundamental el diagnóstico por RM, por ello debe tenerse en cuenta esta entidad ante un dolor abdominal inespecífico con pruebas cardiopulmonares, gastrointestinales y genitourinarias anodinas.

\author{
A.P. Soriano Guillén ${ }^{1}$, E. Mayayo Sinués ${ }^{2}$, S. Cortés \\ Franco $^{3}$ y J.I. Barranco Domínguez ${ }^{4}$ \\ Servicios de ${ }^{I}$ Medicina Física y Rehabilitación, \\ ${ }^{2}$ Radiodiagnóstico, ${ }^{3}$ Neurocirugía y ${ }^{4}$ Cirugía General. \\ Hospital Universitario Miguel Servet. Zaragoza
}

\section{Bibliografía}

1. Quint U, Bordon G, Preissl I, Sanner C, Rosenthal D. Thoracoscopic treatment for single level symptomatic thoracic disc herniation: A prospective followed cohort study in a group of 167 consecutive cases. European Spine Journal 2012;21(4):637-45.

2. McInerney J, Ball PA. The pathophysiology of thoracic disc disease. Neurosurgical Focus 2000;9(4):e1.

3. Barbanera A, Serchi E, Fiorenza V, Nina P, Andreoli A. Giant calcified thoracic herniated disc: Considerations aiming a proper surgical strategy. J Neurosurg Sci 2009;53(1):19-25; discussion 25-6.

4. Rohde RS, Kang JD. Thoracic disc herniation presenting with chronic nausea and abdominal pain: A case report. Journal of Bone and Joint Surgery A 2004;86(2):379-81.

5. Aizawa T, Sato T, Sasaki H, et al. Results of surgical treatment for thoracic myelopathy: Minimum 2-year follow-up study in 132 patients. J Neurosurg Spine 2007;7(1):13-20. 